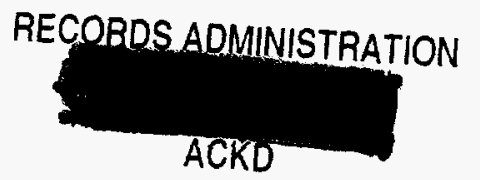

\title{
MAKING AND SUSPENSION CAPABILITIES OF VIBRATORY AGITATORS IN A SLAB TANK
}

by

C. J. Ramsey ${ }^{1}$, E. A. Kyser, $\mathrm{II}^{2}$, and G. B. Tatterson ${ }^{2}$

1 Texas A\&M University

College Station, TX 77843

2 E. I. du Pont de Nemours and Company Savannah River Laboratory Aiken, SC 29808-0001

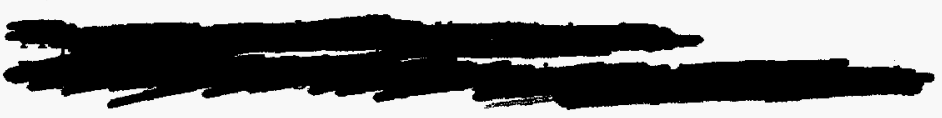

The information contained in this paper was developed during the course of work under Contract No. DE-AC09-76SR00001 with the U. S. Department of Energy. By acceptance of this paper * the publisher and/or recipient acknowledges the U. S. Government's right to retain a nonexclusive, royalty-free license in and to any copyright covering this paper, along with the right to reproduce and to authorize others to reproduce all or part of the copyrighted paper. 


\section{DISCLAIMER}

Portions of this document may be illegible in electronic image products. Images are produced from the best available original document. 


\section{DISCLAIMER}

This report was prepared as an account of work sponsored by an agency of the United States Government. Neither the United States Government nor any agency thereof, nor any of their employees, makes any warranty, express or implied, or assumes any legal liability or responsibility for the accuracy, completeness, or usefulness of any information, apparatus, product, or process disclosed, or represents that its use would not infringe privately owned rights. Reference herein to any specific commercial product, process, or service by trade name, trademark, manufacturer, or otherwise does not necessarily constitute or imply its endorsement, recommendation, or favoring by the United States Government or any agency thereof. The views and opinions of authors expressed herein do not necessarily state or reflect those of the United States Government or any agency thereof.

This report has been reproduced directly from the best available copy.

Available to DOE and DOE contractors from the Office of Scientific and Technical Information, P.O. Box 62, Oak Ridge, TN 37831; prices available from (615) 576-8401.

Available to the public from the National Technical Information Service, U.S. Department of Commerce; 5285 Port Royal Road, Springiield, VA 22161. 


\section{MAKING AND SUSPENSION CAPABILITIES OF}

VIBRATORY AGITATORS IN A SLAB TANK*

by

C. J. Ramsey ${ }^{1}$, E. A. Kyser, $\mathrm{II}^{2}$, and G. B. Tatterson ${ }^{2}$

1 Texas A\&M University

College Station, TX 77843

2 E. I. du Pont de Nemours and Company

Savannah River Laboratory

Aiken, SC 29808-0001

\section{ABSTRACT}

Seven different vibratory agitators, consisting of single and dual flat blade configurations or dual angle blade configurations, were studied for their ability to produce mixing and solid suspension in a slab tank. The mixing behavior of the various configurations was recorded on video tape, and mixing times were measured as the time needed to disperse injected dye. The solid suspension tests, using ash tray sand, were conducted to determine the minimum stroke frequency of the agitators needed for complete off-bottom suspension.

The mixing studies demonstrated that vibratory agitation produced strong vertical fluid motion, good bulk circulation and dispersion in the liquid. The effects of stroke frequency, $n$; amplitude, a; blade width, w; blade clearance, $c$; and liquid depth, $h$, on mixing time, $\theta$, were studied. Single blade geometries produced complete mixing in the least number of strokes.

*The information contained in this paper was developed during the course of work under Contract No. DE-AC09-76SR00001 with the U. S. Department of Energy. 
The solid suspension studies were conducted with only the flat blade geometries. The effects of stroke amplitude, a; blade width, w; slids concentration, $c_{S}$ in wt\%; and liquid depth, $h$, on the complete off-bottom suspension frequency, $\mathrm{n}_{\mathbf{S}}$, were determined. At this frequency, the suspension was dispersed throughout the tank volume up to solid concentrations of approximately $5 \%$ by weight. Above this concentration, the height of the slurry was reduced to 70 to $90 \%$ of the liquid depth, $h$.

The most effective geometry, in terms of both mixing and solid suspension, was a single flat blade with minimum off-bottom clearance and a blade width/tank thickness ratio, $w / T$, of 0.74 at the maximum stroke amplitude of $51 \mathrm{~mm}$.

\section{INTRODUCTION}

In the second stage of a two-stage precipitation process, used in the recovery of plutonium, a suspension of plutonium trifluoride crystals is combined with hydrofluoric acid to induce digestion, crystalization and homogenization. The purpose of agitation in the second stage vessel, known as a slab tank, is to mix thoroughly the contents of the tank and to maintain a homogeneous suspension of solids. With regard to these criteria, it was felt that a non-rotary, updown agitation technique, i.e., vibratory agitation, would be more effective for mixing and solid suspension in slab tanks than traditional rotary mixing techniques that have been used in the past.

The length-height-width proportions of a slab tank are 7-4-1. The shape is the result of nuclear safety considerations; the high ratio of length to width prevents criticality in the processing of the radioactive crystals. The mixing scheme presently employed in production tanks is a symmetrical arrangement of two rotating shafts with multiple impellers. The design is an application of the traditional technology of mixing and solid suspension in cylindrical tanks. However, a slab tank is non-cylindrical and the method of vibratory mixing is non-standard. 
The objectives of this study were: (1) to establish the basic trends in mixing and solid suspension produced by vibratory agitation; and (2) to determine an effective documented mixing and solid suspension geometry for vibratory agitation in a slab tank. Comments on power draw and similarities between vibratory agitation in a non-standard geometry and traditional agitation in a standard cylindrical tank are also given. 1

The development of mixing and solid suspension correlations as a function of geometry is not an objective of this paper.

\section{BACKGROUND}

Very little published literature is available on both mixing and solid suspension in slab tanks, however related research includes: (1) traditional mixing and solid suspension studies in cylindrical tanks; and (2) inertial and drag studies which are pertinent to power draw in vibratory agitation. The hydrodynamic complexities in these areas are well known and experimental results are usually based on dimensional analyses and experimental correlations.

\section{Mixing Times}

In traditional rotary mixing studies in which an efficient mixing impeller is used, the product of impeller rotational speed, $N$, and mixing time, $\theta$, (or circulation time, $\theta_{\mathrm{C}}$ ) is the number of revolutions to mix (or to circulate) a tracer injection throughout a vessel. As an equation, then:

$$
\mathrm{N} \theta=\mathbf{k}
$$

Typically, $\mathrm{k}$ varies from 20 to 80 for efficient rotary mixing geometries and used as an index of the mixing capability of the impeller. For a fixed geometry, $\mathrm{k}$ is constant under either laminar or turbulent rotary mixing conditions. In studies having different mixing geometries, $\mathrm{k}$ is a function of geometry. In the transition regime, $\mathrm{k}$ is dependent upon geometry, the fluid mechanics 
and fluid properties. Mixing time studies in standard rotary agitation are then studies of how $\mathrm{k}$ varies with geometry.

There are few studies involving the mixing capabilities of vibratory agitators. One group of authors mentioned an agitator which utilized a perforated reciprocating plate. ${ }^{2}$ It produced intensive mixing and good circulation at high stroke frequencies, but no quantitative parameters or results were given. One group of researchers working with high-viscosity fluids showed that vibratory agitation provided mixing times comparable to those obtained with the best rotary designs. ${ }^{3}$ Analysts, combining vibratory and rotary motion through a crank-gear system, measured power and mixing time for different impellers and found that the addition of vibratory motion led to a great improvement in agitator performance. 4

Writers found equation 1 to hold for vibratory designs in the laminar regime. They also stated that agitators capable of providing strong axial flow made the best mixers. 5

\section{Solid Suspension}

Most of the research in rotary mixing concerns the minimum impeller rotational speed, $\mathrm{n}_{\mathbf{S}}$, necessary to produce complete off-bottom suspension. Typically, this is the minimum rational speed which permits particles to remain on the tank bottom for only 1 to 2 seconds. The work by Zweitering and other researchers are examples of such work. ${ }^{6}$ The typical correlation for $n_{\mathrm{S}}$, can be written in a power law form:

$$
n_{S}=f\left[(\mu / \rho L)^{a}(\Delta \rho / \rho L)^{b} d_{p} D^{d} c_{S} e(c / T)^{f}(D / T) g\right]
$$

A number of effects are known to exist for rotary agitation. An increase in particle size increases the suspensions speed, $\mathrm{n}_{\mathrm{S}}$, slightly, as does an increase in liquid viscosity or an increase in particle concentration. Increasing the liquid depth to tank diameter ratio $(h / D)$ increases $n_{S}$ to 
some degree. An increase in the impeller to tank diameter ratio $(\mathrm{D} / \mathrm{T})$ causes a decrease in $\mathrm{n}_{\mathrm{s}}$. Increasing the impeller clearance to tank diameter ratio $(\mathrm{c} / \mathrm{T})$ causes an increase in $\mathrm{n}_{\mathrm{s}}$.

Utilizing vibratory agitation, one group of researcher performed a study of solid suspension assuming that the mechanism responsible for suspension in both rotary and vibratory systems was the same. They assumed that the energy imparted by the rotating impeller or vibrating disk induced an axial velocity which suspended the particles. They also assumed that bulk convective flow was responsible for particle liftoff. 8

Studies in vibratory agitation which couple solid suspension, mixing times and non-standard geometries are unavailable.

\section{Inertia and Drag Studies Pertinent to Power Draw}

One team of writers developed a power correlation which allowed for a comparison of vibratory and rotary agitators relative to solid suspension efficiency. ${ }^{9}$ This correlation was based on an equation developed by different researchers to represent the total force acting on a flat plate oscillating in a fluid. The total force was a combination of inertia and drag forces, each characterized by coefficients, $C_{I}$ and $C_{D}$, respectively. 10 However, the basic problem in determination of power draw for vibratory agitation is that inertia and drag vary during an oscillation cycle.

Keulegan and Carpenter utilized dimensional analysis to form the functional relationship for the force, $\mathrm{F}$, acting on an oscillatory plate:

$$
\frac{F}{\rho U^{2}{ }_{m} w L}=f\left(\theta, K, R e_{v}\right)
$$


In the equation above, $\theta$ is a nondimensional time parameter, $\mathrm{K}$ is the Keulegan-Carpenter number (UmT/D or UmT/w), and $\operatorname{Re}_{V}$ is the Reynolds number for oscillating flow. They obtained a Fourier analysis of the periodic force term and developed equations for the weighted averages of the drag and inertia coefficients, $\mathrm{CD}_{\mathrm{D}}$ and $\mathrm{CI}$, over a cycle. Their conclusion was that $\mathrm{CD}$ and $\mathrm{CI}$ are dependent only on $\mathrm{K}$ and that $\mathrm{CD}$ was much larger than $\mathrm{CI}$. No Reynolds number dependence was observed; however, their range in Reynolds numbers was limited, from 4,500 to $14,000.11$

Shih and Buchanan established a strong Reynolds number dependence below 250. For Reynolds numbers greater than this, their results were similar to those of Keulegan and Carpenter. They found that the maximum force occurred when the drag coefficient was near its maximum and the inertia coefficient near zero. 12 Other researchers also found this to be the case, but obtained much higher values of the coefficients, $\mathrm{CD}_{\mathrm{D}}$ and $\mathrm{Cl}_{\mathrm{T}}{ }^{13}$ This was attributed to wall effects which were negligible in the work of Shih and Buchanan.

Martin and Bausano utilized a head-loss coefficient to characterize the net energy dissipation caused by the presence of a flat plate normal to the flow in the base of a large U-tube. ${ }^{14}$ The head loss coefficient was assumed to be constant throughout the period of oscillation and was related to the drag coefficient formulated by Keulegan and Carpenter. 15 Their results were similar to those of others in that the drag coefficient was higher than that in an unconfined situation. 16

Minamizawa and Endoh performed work with a single oscillating disk. 17 Their results were similar to those of Shih and Buchanan and verified a flow transition at low Reynolds numbers. 18 In both studies, the investigators reported a strong coupling of alternating shed vortices above a given oscillation frequency for amplitudes on the order of the body width.

Minamizawa and Endoh measured the effect of distance between two oscillating disks on the drag and inertia forces. When the separation was greater than approximately one disk diameter, 
the forces were doubled. For a critical separation distance less than one diameter, the drag coefficient of the two disks was actually less than the value measured for a single disk. 19

\section{OBJECTIVES}

The specific objectives of this study was to determine how the primary system variables (blade geometry, stroke frequency, n; amplitude, a; blade width, w; and liquid depth, h) affected mixing and solid suspension. For the mixing studies, the dye addition method was adopted. The 1 to 2 second criterion was adopted for the solid suspension studies. A method to calculate maximum power draw is also presented.

\section{EXPERIMENTAL PROGRAM}

\section{Geometry}

The experimental apparatus consisted of the tank and agitator. The slab tank was made of Plexiglas by Moore Fabrication, Houston, Texas, as shown in Figures 1 and 2, with the proportional dimensions of 7,4 , and 1 for length, liquid height, and width. The complete tank, support structure and agitator is shown in Figure 2.

Seven different blade geometries, shown in Figure 3, were investigated. Each blade geometry was given a specific code. The designation, F, FA, or FF, accounts for the gross impeller geometry: F, one flat blade; FA, two blades, one flat and the other at an angle; and FF two flat blades. The second designation, 1,2, or 3, accounts for the differences in geometry in Figure 3. The third designation $36,47,74$, is the impeller blade width in millimeters. The blade thickness was $9.53 \mathrm{~mm}$ for all geometries studied. The slab tank itself was $102 \mathrm{~mm}$ wide at the top of the tank. An additional study of the effect of blade width was performed using widths between 60 to $85 \mathrm{~mm}$. All of the blades had a projected horizontal length of $454 \mathrm{~mm}$. The minimum off-bottom blade clearance, given in Figure 3, was $20 \mathrm{~mm}$ measured from the tank centerline. The off-bottom clearance given for geometry, F-2-74, was referenced from the minimum clearance. 


\section{Mixing Time Studies}

Mixing was studied using tracer injection, and the mixing behavior was recorded on videotape for analysis. A dye injection device injected an equal volume ratio $(0.2 \mathrm{ml} / \mathrm{l})$ of dye at the same location for each test. Very little momentum was added to the liquid in the tank during injection. The mixing studies were performed using tap water. A concentration of $0.2 \mathrm{ml} / \mathrm{l}$ of red or green food coloring provided the necessary contrast. The food coloring did not alter the properties of the fluid. The duration of each mixing test was less than 10 minutes; no increase in water temperature was observed over this time span. The primary dye injection location, $\mathrm{x}$, is shown in Figure 2 in the lower lefthand corner of the tank. Most blade geometries studied were symmetrical and dye injection from either side of the tank was equivalent. In the two asymmetric cases, the effect of injection location on mixing time was investigated.

The vibratory frequency, $n$, of the impeller blade was determined by timing strokes recorded on the videotape. The majority of tests were conducted with a tank volume of 29 liters, which corresponded to a liquid depth, $\mathrm{h}$, of $400 \mathrm{~mm}$ measured from the tank centerline. The effect of liquid depth was studied for the two different blade geometries: F-1-74 and F-2-74, by lowering the depth to $33 \mathrm{~mm}$ and increasing the depth of $480 \mathrm{~mm}$.

The visual contrast between mixed and unmixed fluid was maximized by backlighting the tank. Once mixing appeared to be complete in both the length and height of the tank, it was considered to be complete throughout the tank volume. This was verified by a visual inspection. The mixing endpoint was most readily observed when the negative video image was recorded.

For each blade geometry, a series of mixing tests was recorded for several different stroke frequencies at each stroke amplitude. The frequencies spanned a range from 0.7 to $2.6 \mathrm{~Hz}$ and the amplitudes were 25,38 , and $51 \mathrm{~mm}$. The stroke length of the blade in the slab tank was twice the amplitude or 50,76 , and $102 \mathrm{~mm}$ in length. Mixing was judged to be complete when there was no discernible color contrasts in the liquid. The average mixing times, $\theta$, and standard deviation, 
$\sigma \theta$, were obtained as functions of blade geometry, liquid depth, h; stroke amplitude, a; and. frequency, $\mathrm{n}$. The mixing times were reported as homogenization number, Ho or $\mathrm{n} \theta$, for each mixing test. Mixing times were obtained visually for the additional study of blade width which caused some slight differences in the homogenization data.

\section{Solid Suspension Studies}

The solid suspension studies were performed using generic ash tray silica sand and tap water. The density and mass mean particle size of the sand were $2.63 \mathrm{~g} / \mathrm{cm}^{3}$ and $16 \mu \mathrm{m}$, respectively. The particle size ranged from $75 \mu \mathrm{m}$ to $300 \mu \mathrm{m}$.

Solid suspension produced by vibratory agitation required the presence of at least one flat blade at the tank bottom. All solid suspension work had the blade at the minimum off-bottom clearance of $20 \mathrm{~mm}$ measured at the tank centerline. The effects of stroke frequency $\mathrm{n}$; amplitude, a; blade width, w; solids concentrations, $c_{S}$; and liquid depth, h, were studied. A small mirror was placed directly below the middle of the tank for observation. For each solids concentration, $c_{S}$, the stroke amplitude was varied over the three amplitudes 25,38 , and $51 \mathrm{~mm}$. The frequency at which no particle remained on the tank bottom longer than 1 second was recorded as the complete suspension frequency, $\mathrm{n}_{\mathrm{S}}$. The effect of solids concentration was studied by adding solids to the tank.

The blade geometries used in the solid suspension studies were F-1-47 and F-1-74. The solids concentration was varied from 0.1 to 20.0 weight percent for a liquid volume of 29 liters. For blade geometry F-1-74, the effect of liquid depth was studied by lowering the liquid level from $400 \mathrm{~mm}$ to $300 \mathrm{~mm}$ and later to $180 \mathrm{~mm}$. The depth was changed without changing the mass of solids in the tanks which effectively increased the maximum solids concentration to 57.2 $w t \%$. The maximum height, $h_{S}$, which the slurry obtained was also recorded. 


\section{DIISCÚSSION OF RESULTS}

\section{Mixing Time Studies}

The gross flow pattern, as shown in Figure 4, was followed by the dye during mixing. This pattern, as shown, was approximately the same for all of the geometries studied. The renderings in the figure are idealized in the sense that only the extent of dye circulation is noted. Inhomogeneities within the dyed volume were still present and are not indicated in the figure.

Figure 4 contains four steps in the dispersion of the dye, with two drawings per step corresponding to the two frequencies considered. In all of the figures, step 1 shows the dispersion after one blade stroke $(n \theta=1)$. The number of strokes required to disperse the dye throughout the tank was selected as step 4. The two steps in between were evently divided. between the values of $n \theta$ in steps 1 and 4 . The $n \theta$ values in the fourth step of the figures should not be confused with the homogenization number, Ho, which is the number of strokes required to produce complete mixing. In the fourth step of Figure $4, n \theta$ is the number of strokes required for one completed circulation of the dye:

Arrows in the figure indicate the bulk motion of the dye. This motion was not discernible after one stroke (step 1), but became obvious as mixing progressed. After injection, the dye was forced to the top of the tank as seen in step 2 . Upon reaching the liquid surface, the dye was spread from side to side as seen in step 3. Finally, the dye was swept back toward the bottom of the tank and was dispersed throughout the tank. It was found that the progression of mixing depended upon the number of strokes and not the stroke frequency. This same result is typically obtained with a rotary impeller.

$\mathrm{n} \theta$ or Ho Data. For every geometry studied, the variation in homogenization number was small for a given stroke amplitude. The standard deviations in homogenization number were usually less than $10 \%$ of the mean values. As a result, averaged values for the homogenization number, Ho, were obtained for each blade configuration and amplitude. 
The homogenization numbers for all of the blade geometries at a liquid depth of $400 \mathrm{~mm}$ have been plotted in Figure 5 as a function of the stroke amplitude nondimensionalized by the tank thickness. The lowest homogenization number, Ho $\simeq 18$, was obtained using the widest blade width, F-1-74, at the largest blade amplitude, $51 \mathrm{~mm}$.

Effect of Amplitude. The overall trend in Figure 5 is that, with increasing amplitude, the homogenization number decreases. For a given geometry, an increase in amplitude produces stronger bulk motion throughout the tank and larger zones of intense mixing around the blade. Both lead to lower homogenization numbers. The rate of decrease is not the same however, and is a function of blade width and overall geometry.

Effects of Off-Bottom Clearance and Blade Number and Spacing. Concernịng data of the flat blade geometries with $74 \mathrm{~mm}$ blade width in Figure 5 only, several additional statements can be made. First, an increase in the off-bottom blade clearance, c, as in geometry F2-74, or the blade number, as in FF-1-74, produces an increase in Ho. An increase in the distance, $y$, between the two blades, as in FF-2-74, produces an even greater increase in the homogenization number.

With the blade set at the lowest clearance, the bulk flow was forced upwards in the middle of the tank as shown in step two in Figure 4. When the clearance was increased, the flow was forced upwards not only in the middle, but also up and down along the curved sides of the tank, producing an overall bulk circulation which was weaker than that produced by the blade at the lowest clearance.

A weaker circulation is also produced by an increase in blade number. Apparently the upper blade interfered with the flow produced by the motion of the lower blade. An increase in the distance between the blades magnified the interference, producing even weaker bulk circulation. Both effects increased the homogenization number. 
Effects of Blade Width. The effect of blade width is shown in Figure 6 for the single flat blade geometries and plotted as a function of the blade width/tank thickness ration, $w / T$, for various amplitudes. The off-bottom clearance was $20 \mathrm{~mm}$ and the liquid depth was $400 \mathrm{~mm}$.

The data clearly indicate a minimum in homogenization number of 20 at a dimensionless blade width, w/T of 0.75 The dimensionless blade thickness, $t / T$, was 0.093 . As the stroke amplitude increases, the effect of blade width becomes less pronounced.

Increasing the blade width increased the circulation and hence, led to low Ho values. However, at higher blade widths, wall effects became significant and a minimum in homogenization number appeared as a result. As the blade width approached the tank thickness, a choked condition was reached, circulation approached zero and the homogenization number became very large.

Effects of Blade Angle. To assess the performance of the angled blade geometries, a comparison was made between angled blade and flat blade geometries at the same projected bladed width $(47 \mathrm{~mm})$. The data are shown in Figure 7. Two of the angled blade geometries, FA-2-47 and FA-3-47, had lower homogenization numbers than the single flat blade geometry for the same blade width and stroke amplitude. As in Figure 5, the rate of decrease in Ho with increasing stroke amplitude is geometry dependent.

The addition of the diagonally angled blade in the FA-2-47 and FA-3-47 geometries did not interfere with the bulk circulation, but enhanced it by increasing dispersion in both the vertical and horizontal directions. There was also increased blade area available to produce local mixing with the addition of the second angled blade. 
Geometry FA-1-47, which had a non-diagonal second blade, produced an effect similar to that produced by the addition of another flat blade. The additional blade interfered with the bulk circulation and caused an increase in the homogenization number.

Effects of Liquid Depth. The effects of liquid depth, h, were studied for two geometries, F-1-74 and F-1-74. For both geometries, a decrease liquid depth of 25\% from 400 to $300 \mathrm{~mm}$ produced very little change in the homogenization number for a given amplitude. Intitutively the homogenization number, Ho, should decrease. However, it appeared that partitions divided the slab tank in half at the lower liquid depth. The bulk circulation of dye throughout the tank remained the same which caused the Ho number to remain the same.

An increase in liquid depth resulted in an increase in the homogenization number for a given stroke amplitude.

Effect of Dye Injection Location. The effect of dye injection location was also investigated for the geometries which were asymmetrical, FA-2-47 and FA-3-47. It was found that the injection location had little effect on mixing time for the geometries.

Free Surface Behavior. To some extent, a vibratory agitator is a surface wave generator. During some of the mixing tests, waves formed in the tank and were found to have a critical frequency of $1.3 \mathrm{~Hz}$. The maximum surface wave amplitude observed was $80 \mathrm{~mm}$. Surface waves and splashing were strongly associated with the two diagonally angled blade geometries, FA-2-47 and FA-3-47, because part of the angled blade extended up out of the free surface, and with both dual flat blade geometries, FF-1-74 and FA-3-47, because of the close proximity of the upper blade to the free surface. These geometries were especially susceptible to air entrainment.

The presence of surface waves did not affect mixing and circulation. 


\section{Solid Suspension Studies}

The basic trends in the solid suspension data are shown in Figure 8. The effects of stroke amplitude, $\mathrm{a}$, and blade width, $\mathrm{w}$, on the complete suspension frequency, $\mathrm{n}_{\mathbf{S}}$, are shown as a function of solids concentration.

Effect of Solid Concentration. The most obvious trend in the figure is that $n_{S}$ increases slightly with increasing solids concentration. This is similar to results found by others using a vibrating disk to suspend solids in a cylindrical tank and to results found in rotary agitation literature. ${ }^{20}$

Effect of Blade Width. A decrease in blade width produced an increase in $n_{\mathbf{S}}$. Generally, solids were drawn up into the wake of the blade on each upward stroke. However, the intensity for the flow in this region, for a given amplitude, was dependent on blade width and frequency. For a given frequency, a wider blade drew more fluid upward in its wake, producing stronger downward drafts at the wall and higher velocities at the tank bottom. Assuming that a given velocity at the tank bottom is required for completed suspension, a decrease in blade width led directly to a higher complete suspension frequency, $\mathrm{n}_{\mathrm{S}}$, to obtain the same suspension velocity at the tank bottom. This trend appeared to be independent of stroke amplitude. No data were taken above $w / T=0.75$ but it is suspected that $n_{S}$ will increase drastically as $w / T$ approaches one and choking conditions occur.

Amplitude Effect. For a given blade width, an increase in amplitude produces a increase in $\mathrm{n}_{\mathrm{S}}$. The flow velocity in the wake of the blade increases with increasing stroke amplitude for a given blade width and stroke frequency. Assuming that a fixed velocity at the tank bottom is required for complete suspension, an increase in amplitude would lead to a lower suspension frequency ns.

Effect of Liquid Depth. The effect of $n_{S}$ remains constant or decreases slightly with a decrease in liquid depth, $\mathrm{h}$, which indicates that solid suspension is a local phenomenon occurring at the tank bottom. 


\section{Slurry Flow Behavior}

Observations were made regarding the general behavior of the suspended slurry. In all cases, the solids were carried upward in the middle of the tank and were spread from side to side by the strong bulk circulation. Below a solids concentration of approximately $5 \%$, the slurry rose to the free surface and effectively occupied the entire tank volume. The behavior was very similar to the dispersion of dye. Above $5 \%$ solids concentration, the slurry height, $h_{\mathbf{S}}$, was dependent on blade width, w, and stroke amplitude, a. This dependence is indicated in Figure 9, where the suspension height to liquid depth ratio, $h_{S} / h$, is plotted as a function of solids concentration for both geometries F-1-74 and F-1-47 at the three amplitudes used in the study. All of the data in this figure come from tests performed with a liquid depth, h, of $400 \mathrm{~mm}$.

\section{Correlation for the Drag Coefficient}

Although there were no power data obtained in this study, the results of previous work were used to develop a drag coefficient correlation which could be used for the determination of the maximum power draw of the our vibratory agitator. The equation developed by earlier studies stated that the total force of a vibrating object was a combination of inertia and drag forces. Each of these was characterized by a coefficient, $\mathrm{CI}_{\mathrm{I}}$ or $\mathrm{CD}_{\mathrm{D}} .21$ However, in the low KeuleganCarpenter number range below 20 , the drag coefficient, $\mathrm{CD}$, was found to dominate the inertia coefficient, CI, in all previous work. Further, in studies by other researchers, the maximum force was found to coincide with the maximum value of the drag coefficient. 22

In our study, the Keulegan-Carpenter number varied from 1.8 to 8.9 and the dominance of the drag force over the inertia force was assumed. As a result, only the drag coefficient correlations from the previous studies were considered important of the power draw of the vibratory agitator used in the study. 
Figure 10 contains a summary of the variation of the drag coefficient, $\mathrm{CD}_{\mathrm{D}}$, as a function of the Keulegan-Carpenter number and a width ratio for oscillating disks and flats plates. The width ratio, $w / T$, indicates the effect of increasing flow restriction. In a study performed by others, the drag coefficient was plotted as a function of the Reynolds number, but it was possible to determine the envelope of their drag coefficient data as a function of Keulegan-Carpenter number based upon the experimental conditions. 23 These envelopes are also shown in Figure 10.

Form the data show, a value of -0.5 appears to be an appropriate power law exponent for the dependency of the drag coefficient on the Keulegan-Carpenter number. Previous power law fits provided exponents between -0.33 and -0.57 .24 The extrapolation of the data on oscillating flat plates obtained by Martin and Bausano into the range of our work is also justified by dimensional analysis arguments. 25

The dependency of the drag coefficient, $\mathrm{CD}$, on both the Keulegan-Carpenter number, $\mathrm{K}$, and the width ratio, $w / T$, was obtained as:

$$
\mathrm{CD}=111 \mathrm{~K}-0.5(\mathrm{w} / \mathrm{T})^{-0.87}
$$

In the above equation, $0.5<\mathrm{k}<50$ and $0.1<\mathrm{w} / \mathrm{T}<0.75$ should be noted. The correlation is shown in Figure 11. For $(w / T)<0.1$, the value of $\mathrm{CDK}^{0.5}$ would be expected to remain constant since any flow restriction in this region is negligible. As $w / T$ approaches one, the value of the drag coefficient, $\mathrm{CD}$, would increase sharply. The effect of off-bottom clearance was not incorporated into the drag coefficient correlation.

In the mixing studies, a value of $w / T=0.75$ was identified as the point where optimum mixing occurred and the homogenization number was a minimum. For higher values of $w / T$, the homogenization number increased sharply. 
The power draw from the impeller to the fluid can be estimated from the drag coefficient as shown in the following sample calculation.

Sample Calculation. For a blade width $\mathrm{w}=77 \mathrm{~mm}$, amplitude $\mathrm{a}=51 \mathrm{~mm}$, tank width $\mathrm{T}$ $=102 \mathrm{~mm}$, blade length $\mathrm{L}=454 \mathrm{~mm}$, at a stroke frequency of $1.5 \mathrm{~Hz}$, the drag coefficient is:

$$
\begin{aligned}
C_{D} & =111 \mathrm{~K}-0.5(\mathrm{w} / \mathrm{T})^{0.87} \\
& =42.4
\end{aligned}
$$

Note $K=2 \pi \mathrm{a} / \mathrm{w}$ and $w / T=0.75$. Assuming the properties of water at STP, the maximum agitator power draw is:

$$
\begin{aligned}
P_{\max }=F_{d v_{m}} & =0.5 C_{D} \rho\left(V_{m}\right)^{3} L w \\
& =0.33 \text { watts }
\end{aligned}
$$

In the above equation, $F_{D}$ is the drag force and $V_{m}$ is the amplitude times the stroke frequency or an. The power per volume is $11 \mathrm{w} / \mathrm{m}^{3}$ assuming the tank volume is $0.03 \mathrm{~m}^{3}$.

\section{CONCLUSION}

Vibratory agitation was capable of producing mixing and solid suspension in a slab tank. Of the geometries studies, the single flat blade configuration with a minimum off-bottom clearance and $\mathrm{a} w / \mathrm{T}$ of 0.75 was considered to be the most effective for mixing and solid suspension requirements in a slab tank.

Vibratory mixing in a slab tank was very similar to rotary mixing. The homogenization number, Ho, the number of revolutions or strokes required to obtain complete mixing, was constant for a given geometry with the stroke amplitude included in the geometry specification. The type of bulk motion induced by a vibratory agitator was very effective in the production of a homogeneous slurry. Particles were pulled off the tank bottom, drawn into the bulk circulation, 
and dispersed throughout the tank. The general solid suspension behavior in vibratory mixing was also very similar to rotary mixing.

\section{ACKNOWLEDGMENTS}

This work was performed under SRL Contract AX 0798886. The help and support of E. W. Holtzscheiter and C. R. Goetzman of SRL and T.P.K. Chang of E. I. du Pont are gratefully acknowledged.

\section{REFERENCES CITED}

1. C. J. Ransey, "An Investigation of the Mixing and Solid Suspension Capabilities of Vibratory Agitators in a Slab Tank," MS Thesis, Mechanical Engineering Department, Texas A\&M University, College Station, TX 1988.

2. R. L. Bates, P. L. Fondy, and J. G. Fenic, "Impeller Characteristics and Power," Mixing, Volume 1, V. W. Uhl, and J. B. Gray, eds., Academic Press, New York, NY, Chapter 3, pp. 112-176, 1966.

3. S. Nagata, M. Nishikawa, T. Katsube, and K. Takaish, "Mixing of Highly Viscous NonNewtonian Liquids," Intern. Chemical Eng., 12, pp. 175-182, 1972.

4. Y. Murakami, T. Hirose, T. Yamato, H. Fujiwara, and M. Ohshima, "Improvement in Mixing of High Viscosity Liquid by Additional Up-Down Motion of a Rotating Impeller," J. Chem. Eng. Japan, 13, pp. 318-323, 1972.

5. Nagata, Nishikawa, Katsube, andj Takaish, pp. 175-182.

Murakami, Hirose, Yamato, Fujiwara, and Ohshima, pp. 318-323.

6. G. Baldi, R. Conti, and E. Alaria, "Complete Suspension of Particles in Mechanically Agitated Vessels," Chem. Eng. Sci., 33, pp. 21-25, 1978.

T. N. Zweitering, "Suspending of Solid Particles in Liquid by Agitators," Chem. Eng. Sci, 8, pp. 244-253, 1958. 
7. J. B. Gray, and J. Y. Oldshue, "Agitation of Particulate Solid-Liquid Mixtures," Mixing, Volume 3, V. W. Uhl, J. B. Gray, eds., Academic Press, Orlando, FL, Chapter 12, pp. 1 $61,1986$.

8. K. Tojo, K. Miyanami, and H. Mitsui, "Vibratory Agitation in Solids - Liquid Mixing," Chem. Eng. Sci., 36, pp. 279-284, 1981.

9. K. Tojo, K. Miyanami, and T. Yano, "Power Dissipation in a Vibrating Disk Column," Chem. Eng. J., 17, pp. 211-218, 1979.

Tojo, Miyanami, and Mitsui, pp. 279-284, 1981.

10. G. H. Keulegan, and L. H. Carpenter, "Forces on Cylinders and Plates in and Oscillating Fluid," J. Res. Nat. Bur. Standards, 60, pp. 423-440, 1958.

M. Minamizawa, and K. Endoh, "Effect of Distance Between Disks on Fluid forces Exerted on Two Disks Oscillating in Water," Kagaku Kogaku Ronbunshu, 10, pp. 389-391, 1984.

M. Minamizawa, and K. Endoh, "Fluid Resistance on a Disk Oscillating Sinusoidally in a Liquid," J. Chem. Eng. Japan, 17, pp. 186-191, 1984.

J. R. Morison, M. P. O'Brien, J. W. Johnson, and S. A. Schaff, "The forces Exerted by Surface Waves on Piles," J. Pet. Tech., AIME, 189, pp. 149-160, 1950.

C. C. Shih, and H. J. Buchanan, "The Drag on Oscillating Flat Plates in Liquids at Low Reynolds Numbers," J. Fluid Mech., 48, pp. 229-239, 1971.

Tojo, Miyanami, Minami, and Yano, pp. 211-218, 1979.

11. Keulegan, and Carpenter, pp. 423-440.

12. Shih, and Buchanan, pp. 229-239.

13. Tojo, Miyanami, Minami, and Yano, pp. 211-218, 1979.

14. C. S. Martin, and J. C. Bausano, "Oscillating Flow Over a Flat Plate Normal to a Wall," Adv. Civil Eng. Through Eng. Mech.: Proc. Second Annual Engineering Mechanics Division: Specialty conference, North Carolina State University, Raleigh, NC, Engineering Mechanics Division, ASCE, New York, pp. 528-531, May 23-25, 1977.

15. Keulegan, and Carpenter, pp. 423-440.

16. Tojo, Miyanami, Minami, and Yano, pp. 211-218, 1979. 
17. Minamizawa, Endoh.

18. Shih, and Buchanan, pp. 229-239.

19. Minamizawa, Endoh.

20. Tojo, Miyanami, and Mitsui, pp. 279-284, 1981.

21. Morison, O'Brien, johnson, and Schaff, pp. 149-160.

22. Shih, and Buchanan, pp. 229-239.

Tojo, Miyanami, Minami, and Yano, pp. 211-218, 1979.

23. Tojo, Miyanami, Minami, and Yano, pp. 211-218, 1979.

24. B. De Brenardinis, J. M. R. Graham, and K. H. Parker, "Oscillatory Flow Around Disks and Through Orifices," J. Fluid Mech., 102, pp. 279-299, 1981. Minamizawa, and Endoh.

25. Martin, and Bausano, pp. 528-531.

\section{OTHER REFERENCES NOT CITED}

J. M. R. Graham, "The Forces on Sharp-Edged Cylinders in Oscillatory Flow at Low KeulegenCarpenter Numbers," J. Fluid Mech., 97, pp. 331-346, 1981. 
a

c

$\mathrm{c}_{\mathrm{S}}$

$\mathrm{CD}$

CI

$\mathrm{d}_{\mathrm{p}}$

D

$F$

FD

h

$\mathrm{h}_{\mathrm{S}}$

Ho

k

K

$\mathrm{L}$

n

$\mathrm{n}_{\mathbf{S}}$

$\mathrm{N}$

$\mathrm{P}_{\max }$

$\operatorname{Re}_{\mathrm{V}}$

t

$T$

$\mathrm{U}_{\mathrm{m}}$

w amplitude

off-bottom blade clearance

solids concentration (wt\%)

drag coefficient

inertial coefficient

particle diameter

impeller or plate diameter

force

drag force

liquid height

slurry height

homogenization number

revolutions for mixing

Keulegan Carpenter Number, $U_{\mathfrak{m}} \tau / D$ or $U_{\mathfrak{m}} \tau / \mathrm{w}$.

blade length

stroke frequency

complete off-bottom suspension stroke frequency or rotational speed

impeller rotational speed

maximum power draw

Reynolds number for oscillating flow

blade thickness

tank thickness or tank diameter

maximum velocity of stroke, an

blade width

\section{Greek Symbols}

$\Delta p \quad$ density difference between solid and liquid

$\rho, \rho L \quad$ density of liquid

$\theta, \theta_{c} \quad$ mixing time, circulation time

$\mu \quad$ viscosity

$\varphi \quad$ nondimensional time parameter

$\tau \quad$ stroke period

$\sigma \theta$ standard deviation in mixing time 


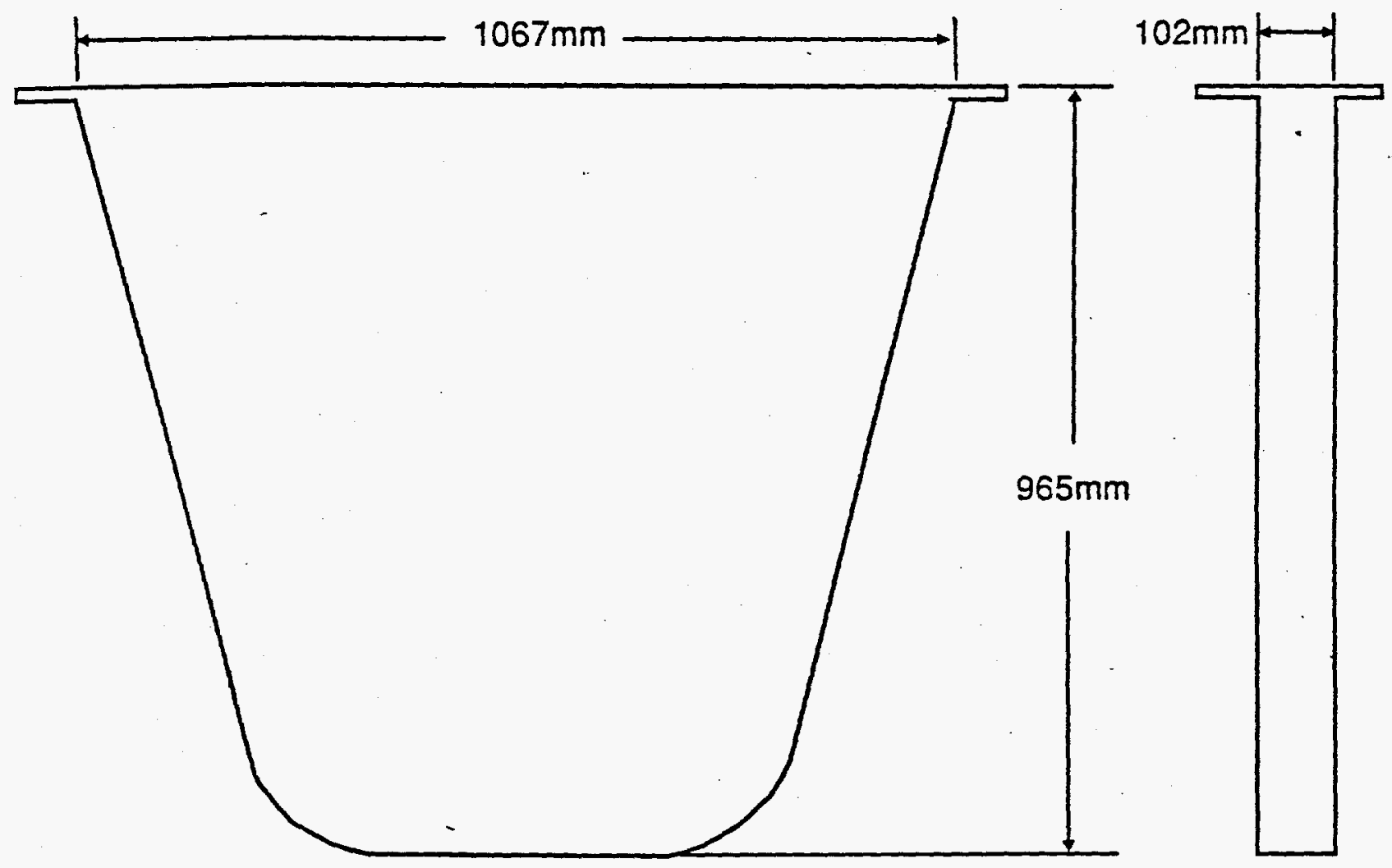

Figure 1: Slab Tank Geometry 


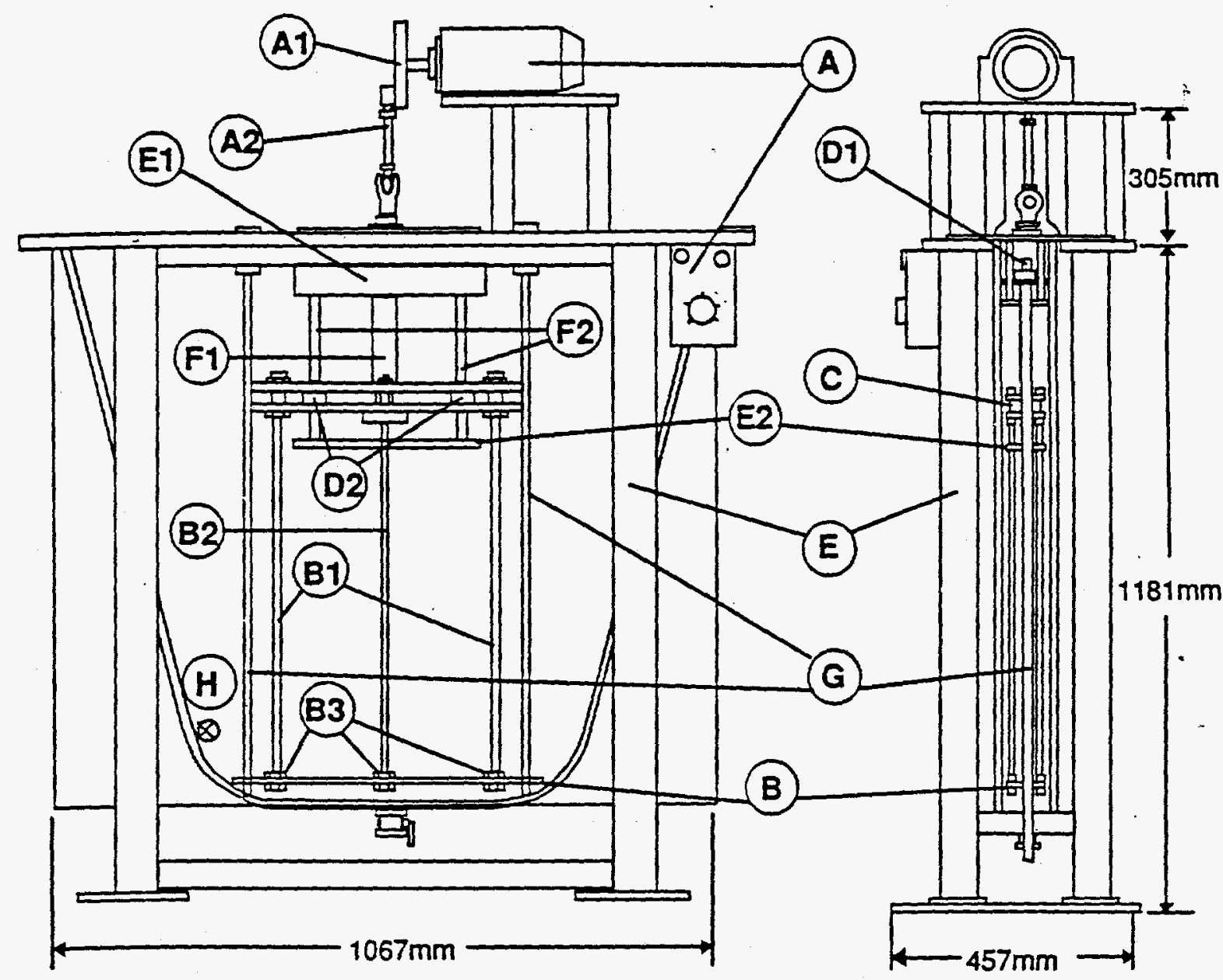

(dimensions in millimeters)
(A) variable speed motor
(D1) main bearing
(A1) crank wheel
(D2) secondary bearing
(A2) connecting rod
(E) base
(B) blade structure
(E1) main bearing base
B1) PVC threaded rod
(E2) plate
(B2) stainless steel threaded rod
(F1) main shaft
(B3) locknuts
F2 secondary shaft
(C) blade support structure
(G) teflon-coated stbilizer
(H) dye injection location

Figure 2: Experimental Apparatus Showing Tank, Mixer and Tank Support 


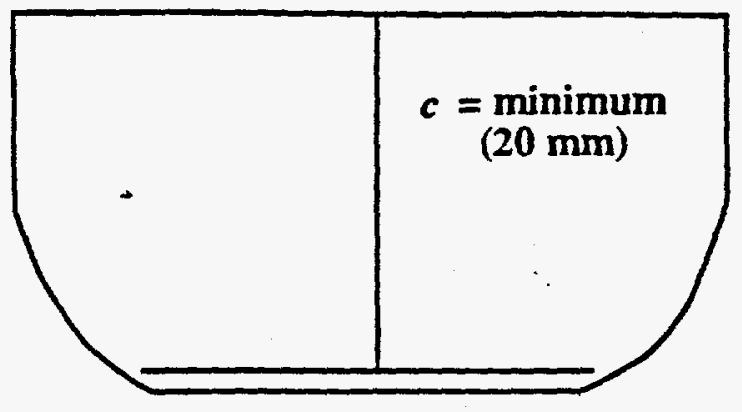

(1) F-1-74, 47, $36 \mathrm{~mm}$

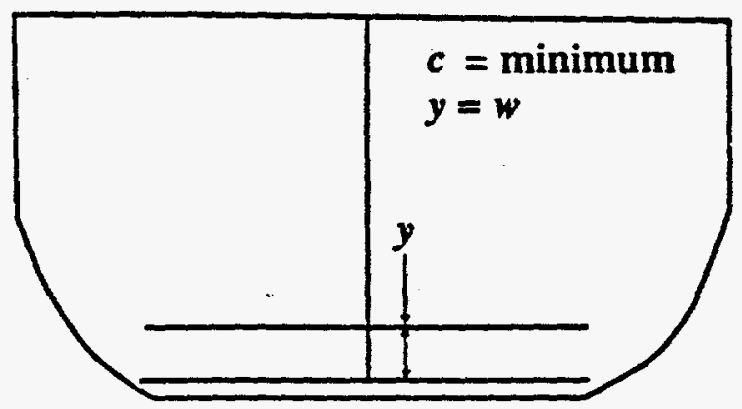

(3) FF-1-74mm

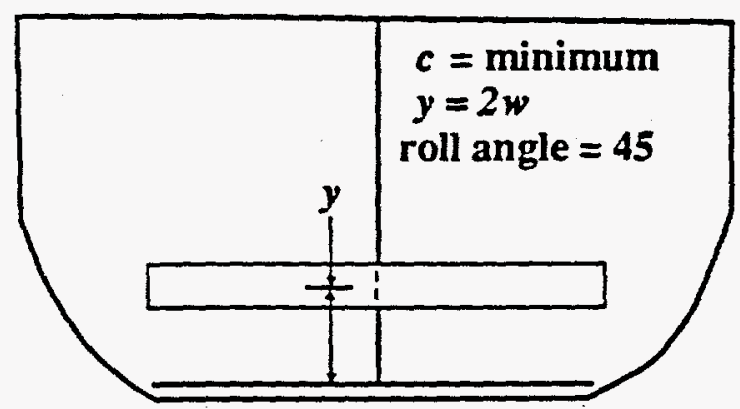

(5) FA-1-47mm

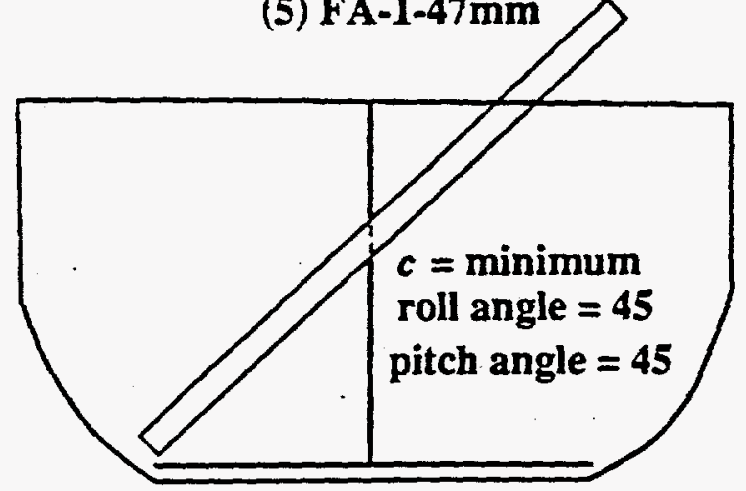

(7) FA-3-47mm

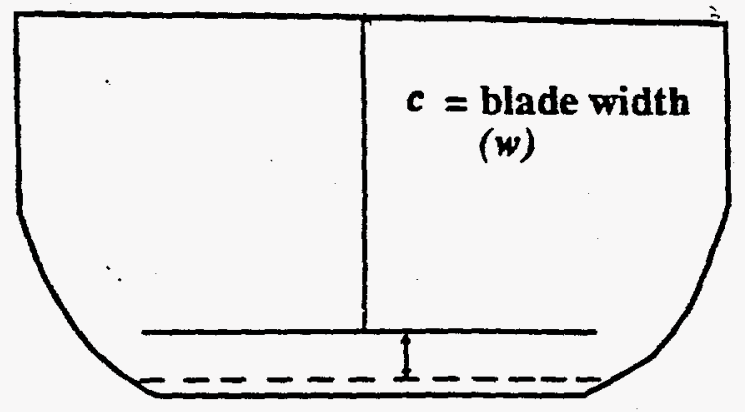

(2) F-2-74 mm

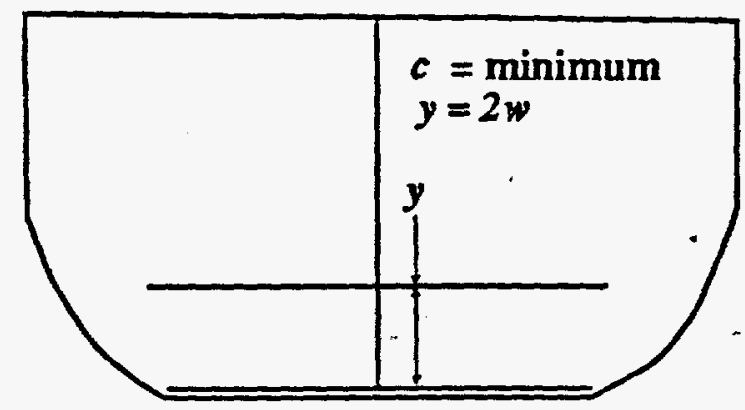

(4) FF-2-74mm

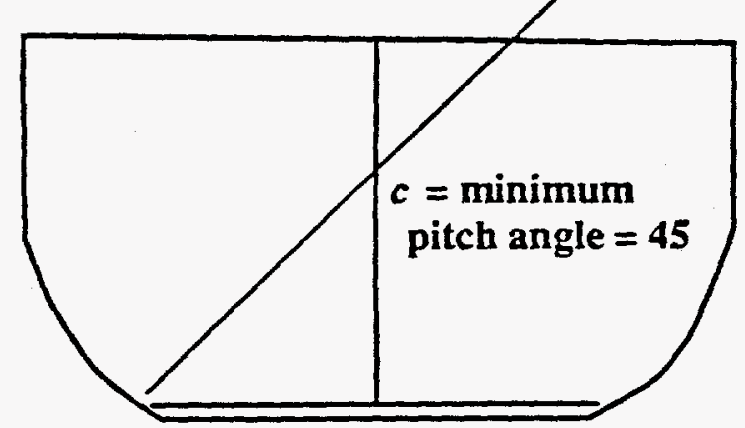

(6) FA-2-47mm

Figure 3: Blade Geometries and Associated Nomenclature 


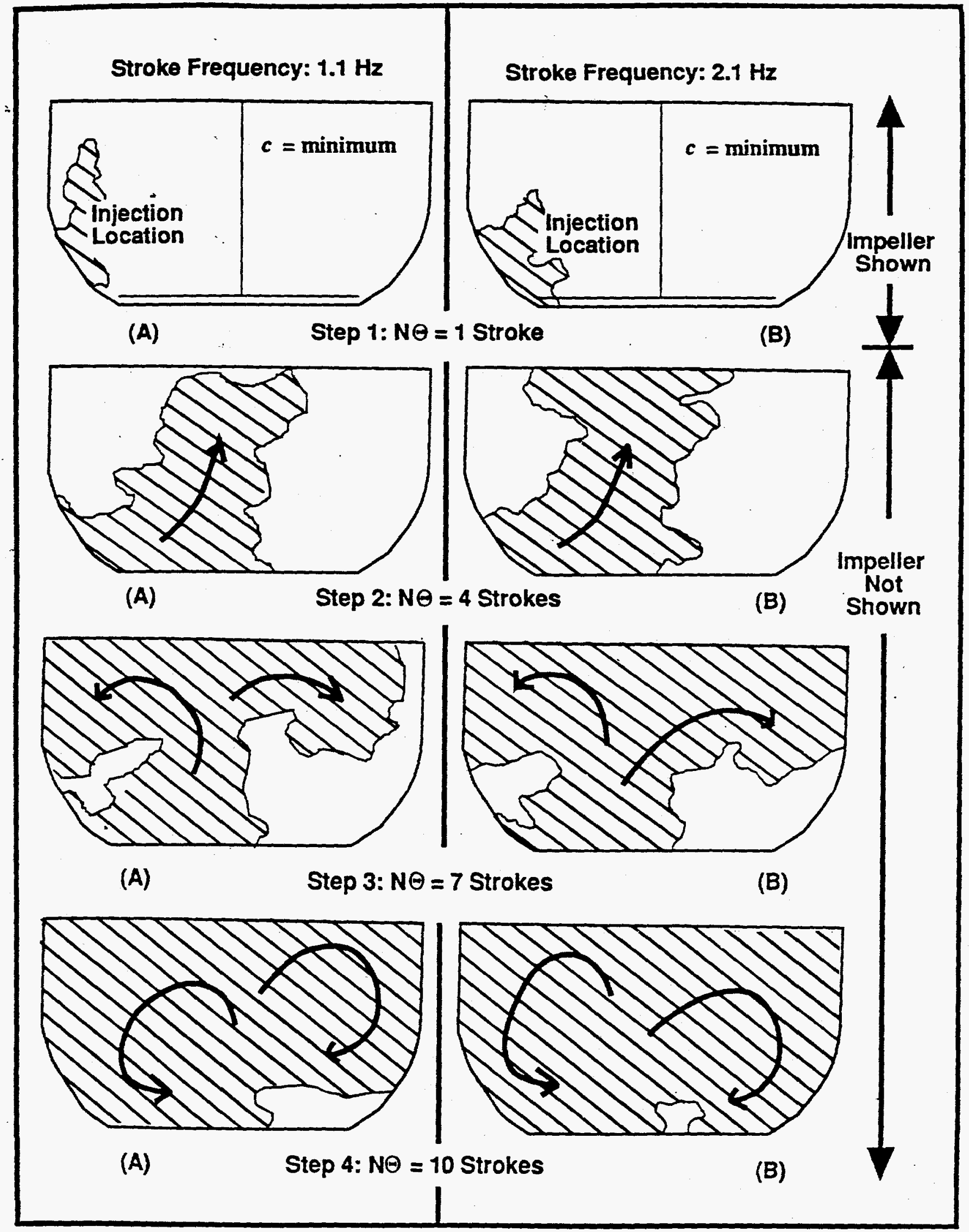

Figure 4: Idealized Dye Dispersion for Geometry F-1-74 for Stroke

Frequencies of: (A) $1.1 \mathrm{~Hz}$ and (B) $2.1 \mathrm{~Hz}$ with Stroke Amplitude $=38 \mathrm{~mm}$, Liquid Height $=400 \mathrm{~mm}$ 


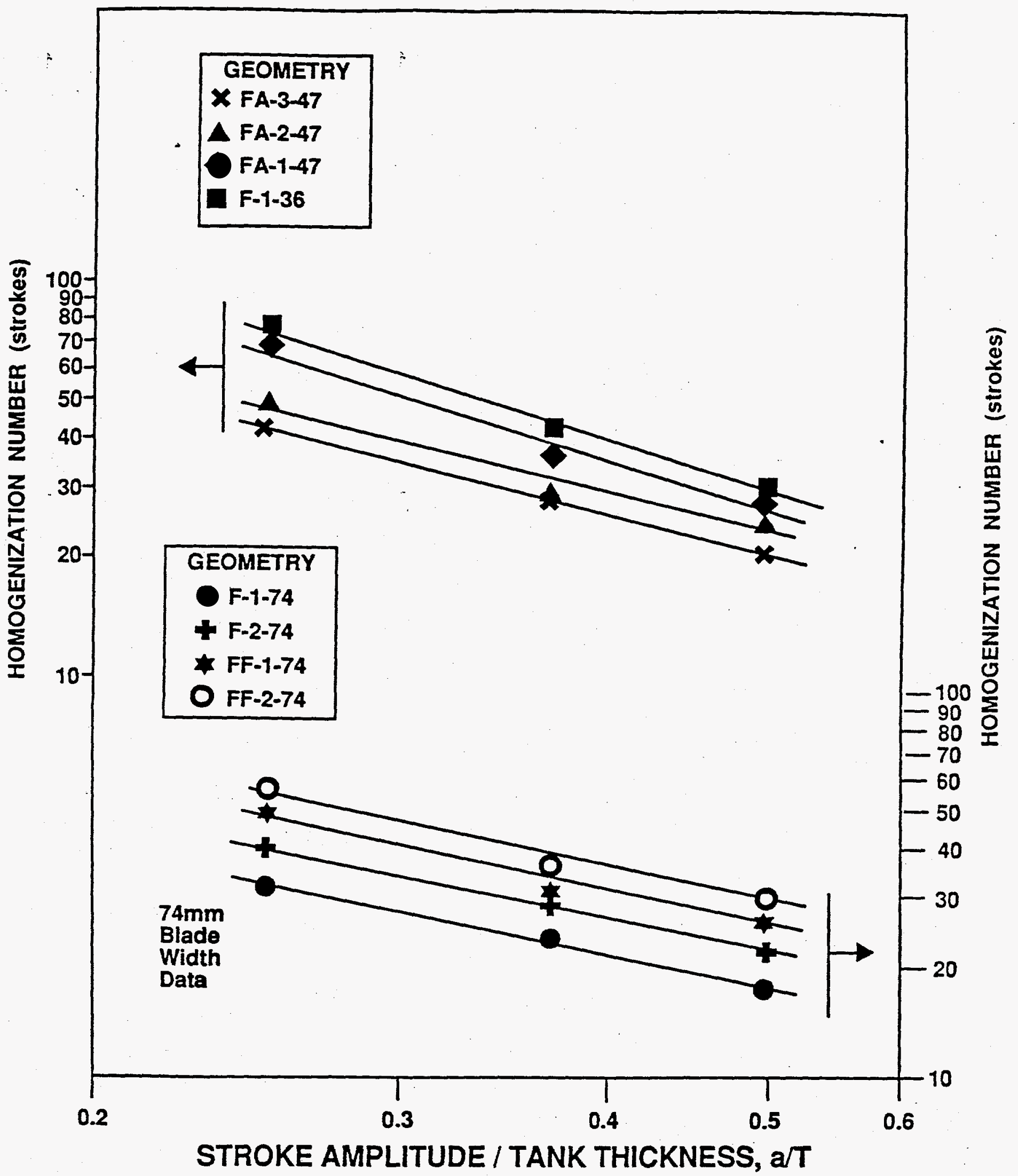

Figure 5: Homogenization Number versus Dimensionless Amplitude for All Geometries, Liquid Height $=400 \mathrm{~mm}$. 


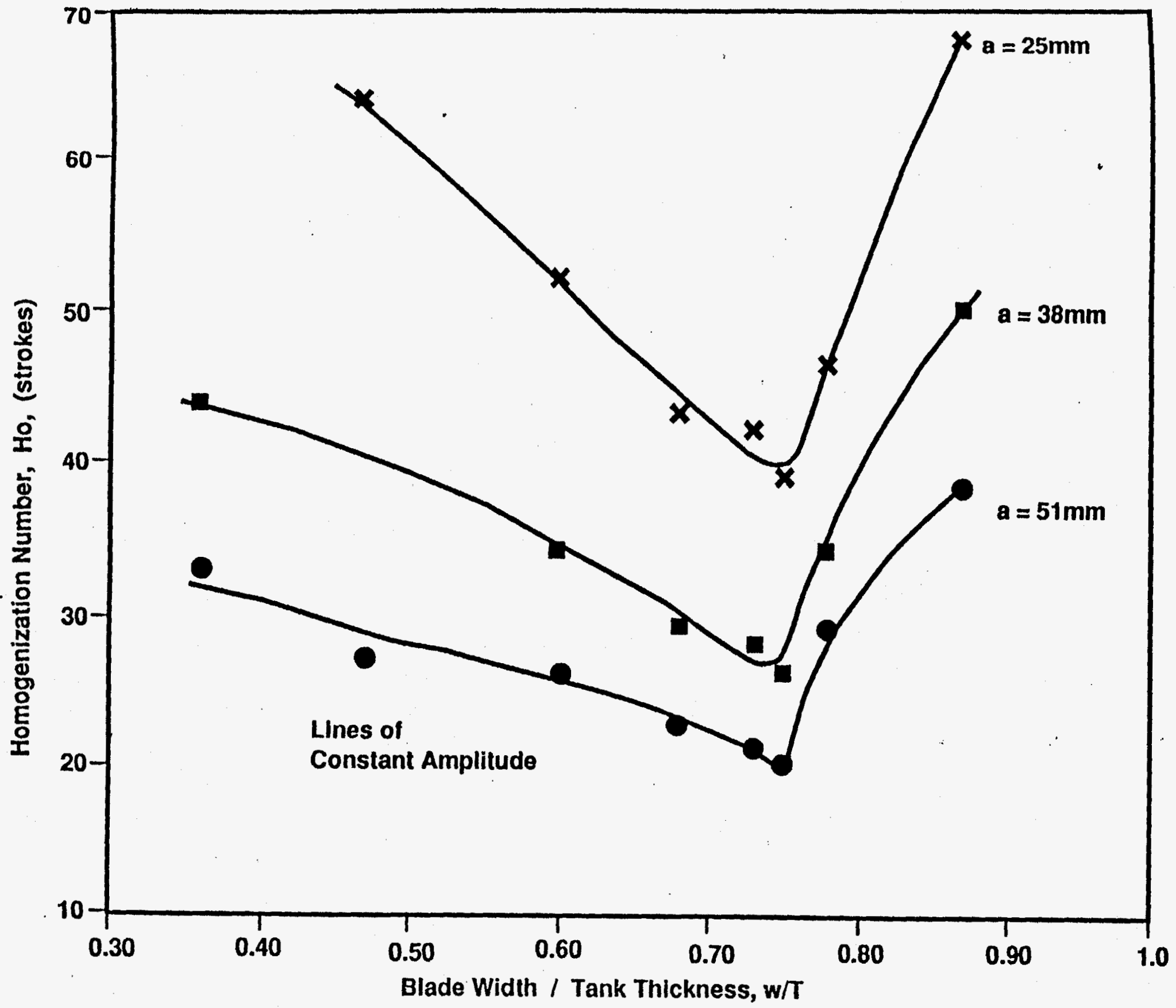

Figure 6: The Effect of Blade Width upon the Homogenization Number for Different Amplitudes, Liquid Height $=400 \mathrm{~mm}$, Minimum Off-Boltom Clearance $c=20 \mathrm{~mm}$. 


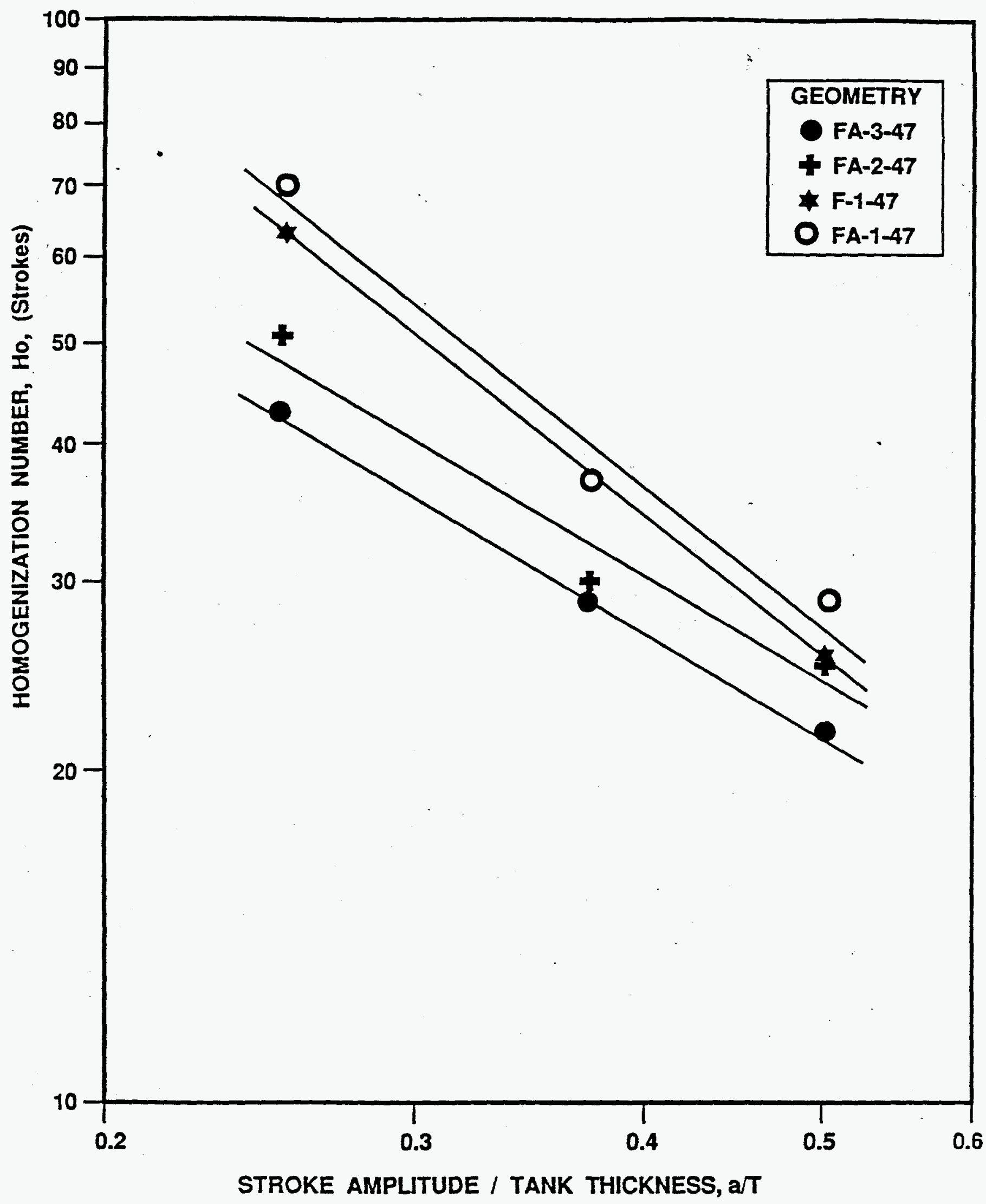

Figure 7: A Comparison between Flat and Angled Blade Geometries, Blade Width $=47 \mathrm{~mm}$, Liquid Height $=400 \mathrm{~mm}$. 


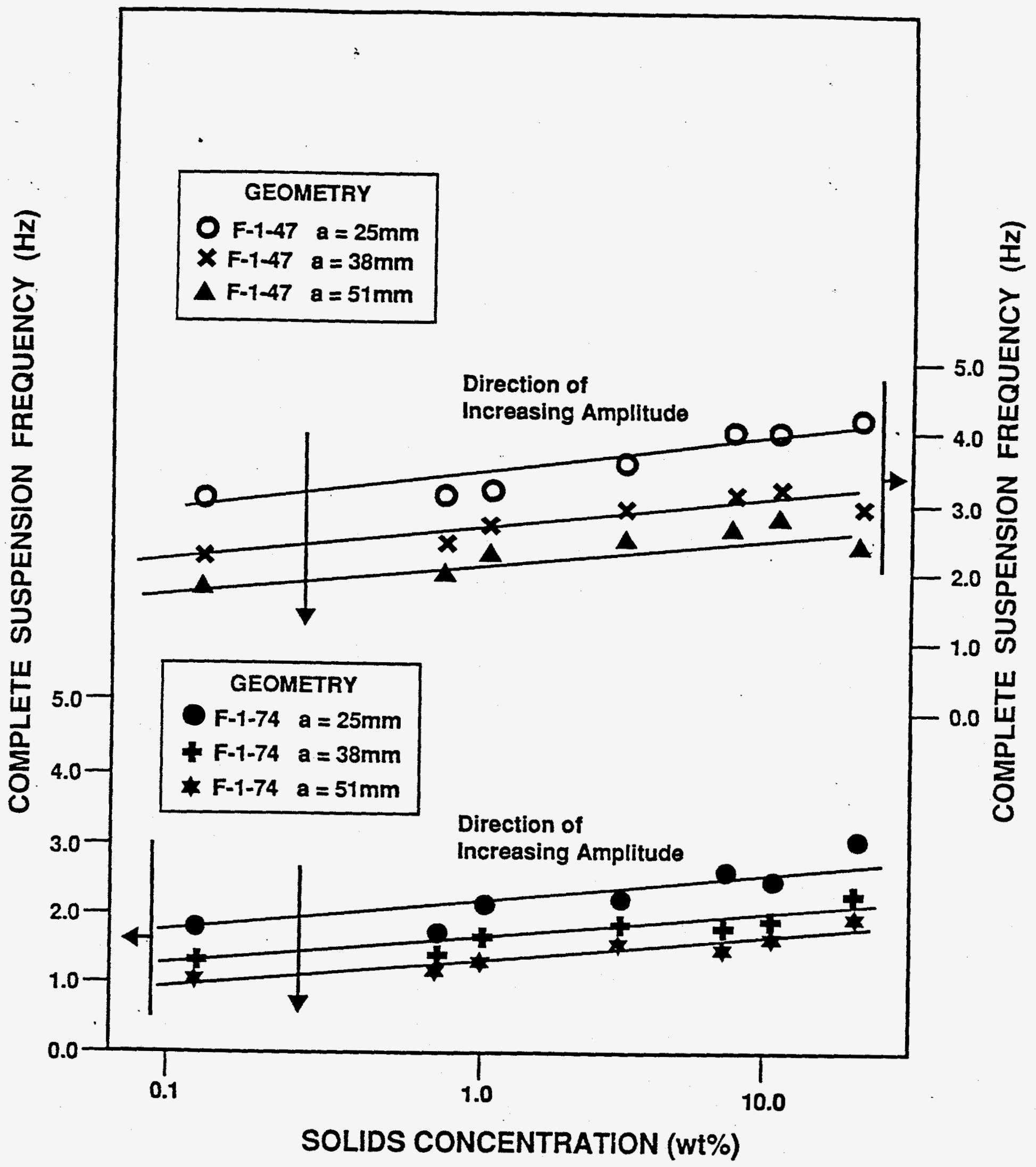

Figure 8: Change in $n_{S}$ with Solids Concentration (wt\%), Liquid Height $=400 \mathrm{~mm}$, Minimum Off-Bottom Clearance, $c=20 \mathrm{~mm}$ 


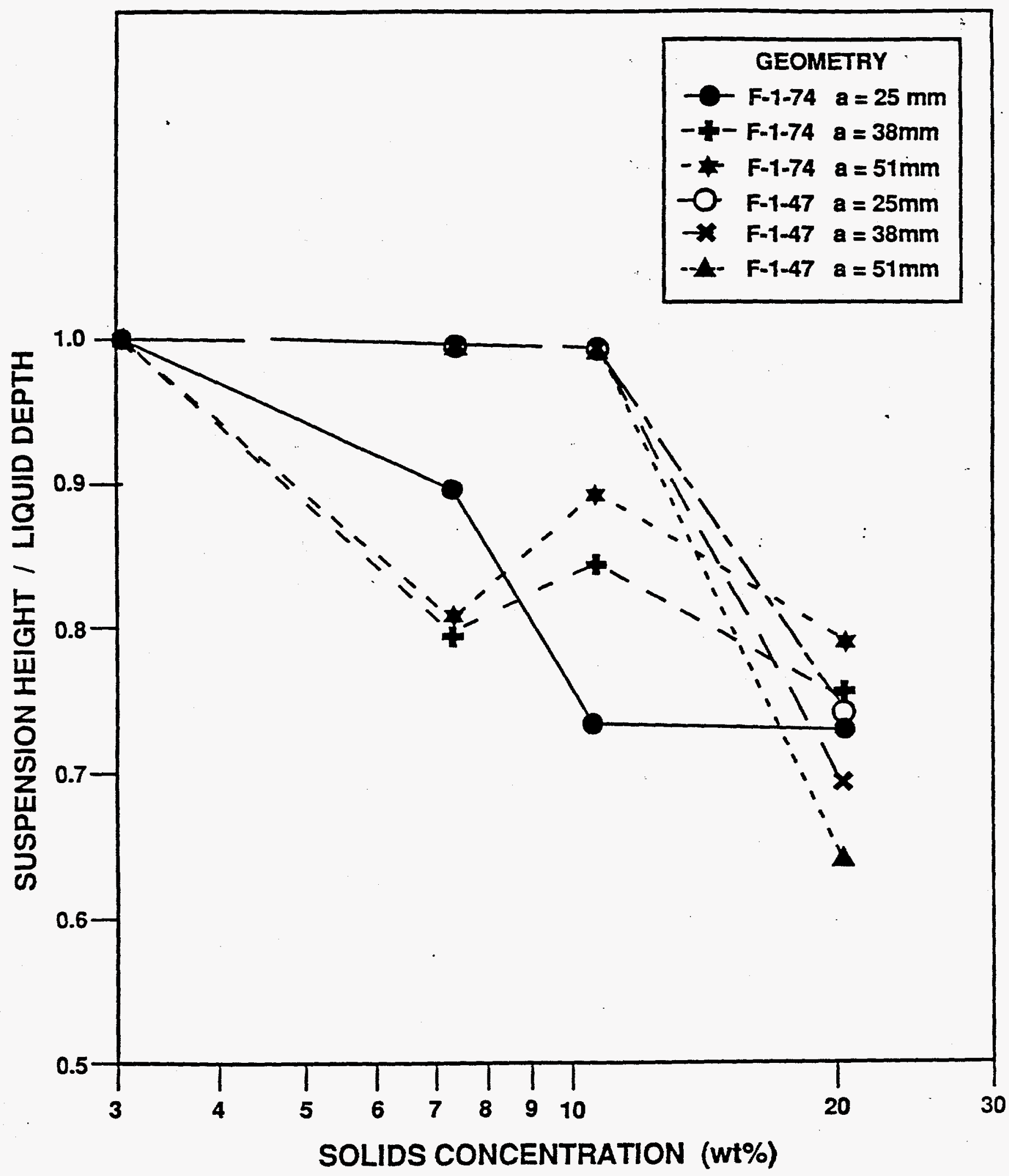

Figure 9: Change in $h_{S} / h$ with Increasing Solids Concentration, Liquid Height $=400 \mathrm{~mm}$ 

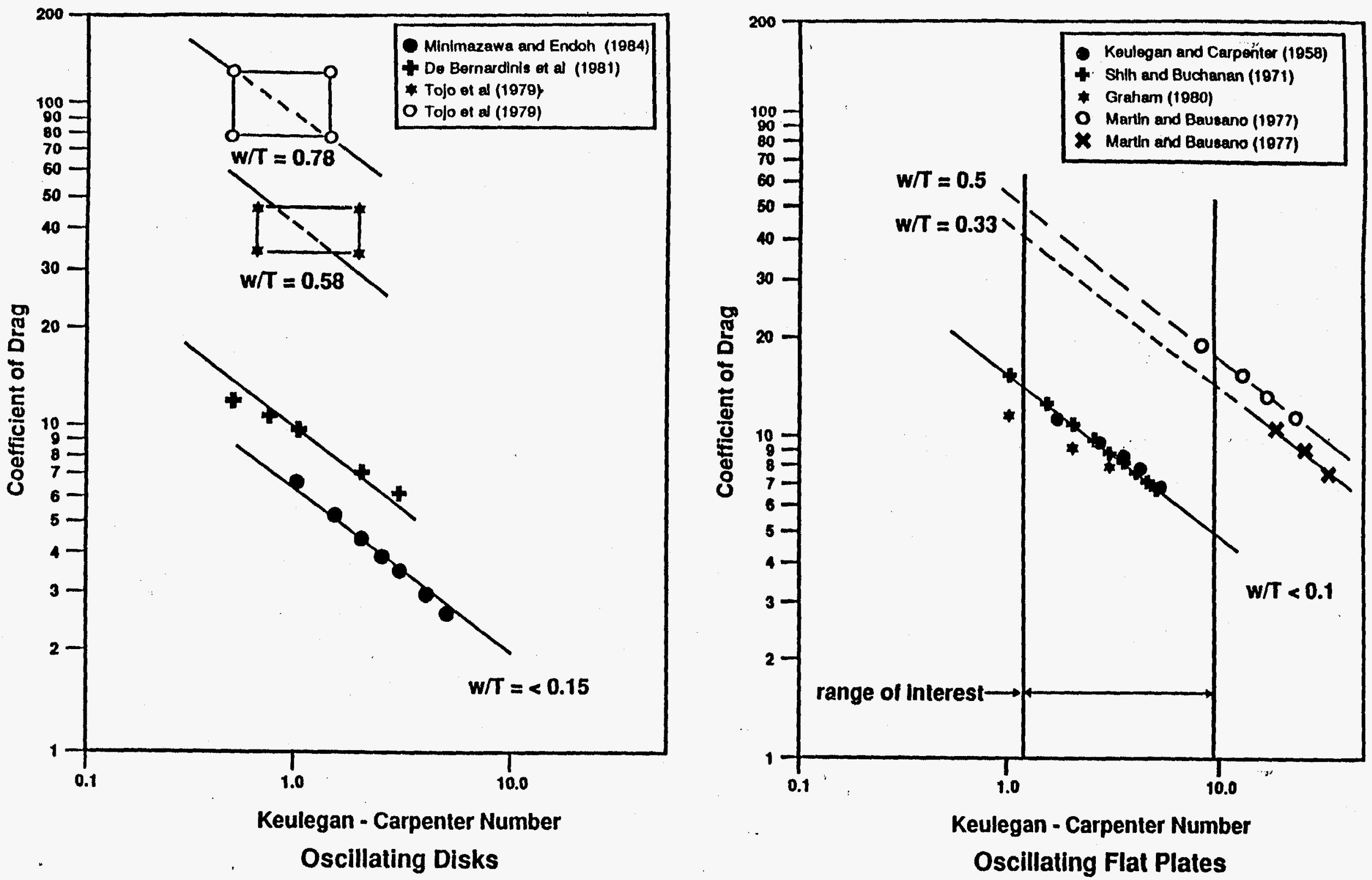

Figure 10: Drag Coefficient as a Function of the Keulegan - Carpenter Number and Blade Width Ratio, w/T 


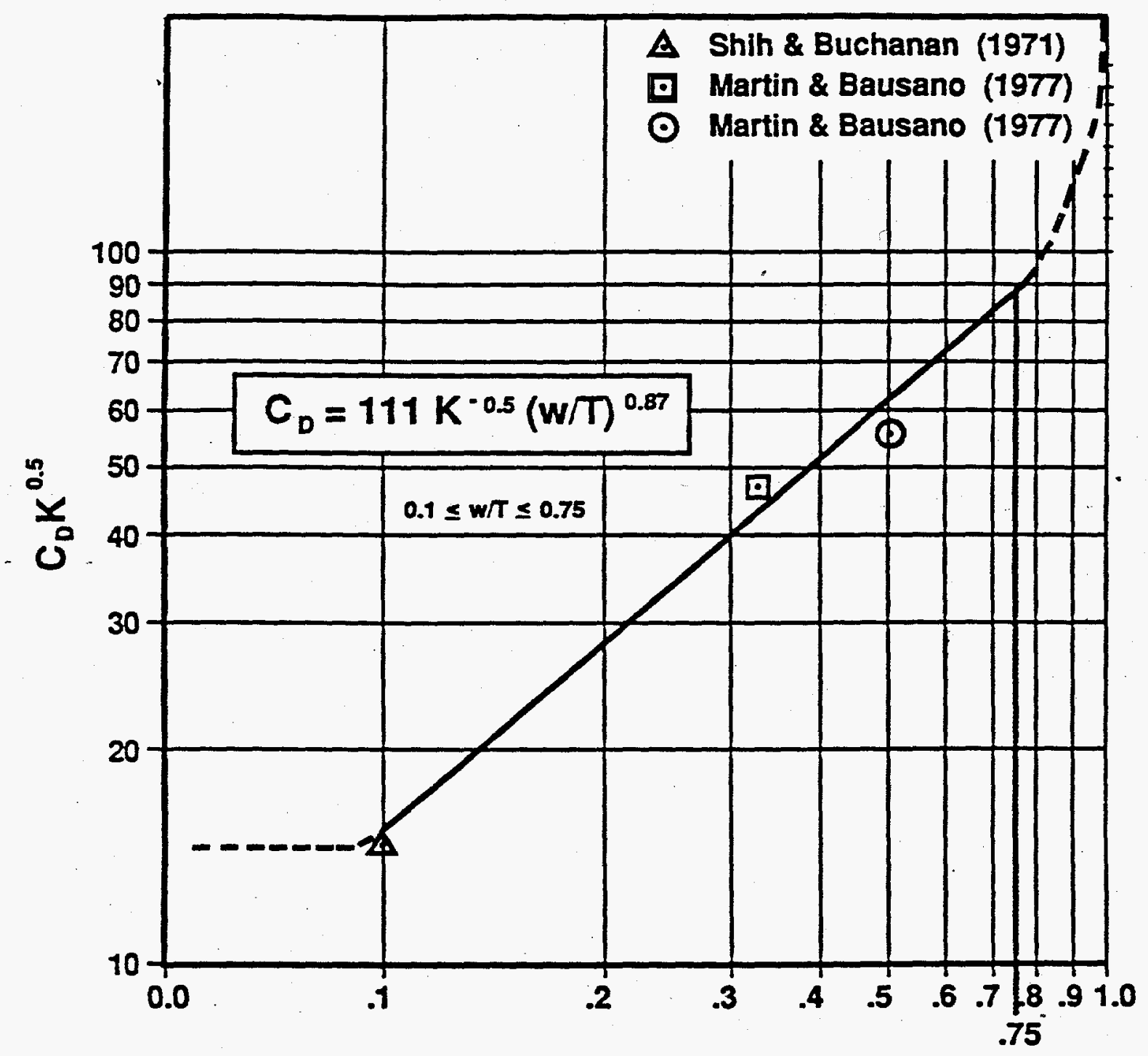

Blade Width / Tank Thickness, w/T

Figure 11: Drag Coefficient Correlation for Flat Plates 